\title{
Erratum to: Physiologically Based Pharmacokinetic Modeling of Impaired Carboxylesterase-1 Activity: Effects on Oseltamivir Disposition
}

\author{
Zhe-Yi Hu • Andrea N. Edginton · S. Casey Laizure • \\ Robert B. Parker
}

Published online: 21 August 2014

(c) Springer International Publishing Switzerland 2014

\section{Erratum to: Clin Pharmacokinet \\ DOI 10.1007/s40262-014-0160-3}

A Published-Ahead-of-Print version of this article was made available online on 08 August 2014. Errors have subsequently been identified in that version of the article, and the following corrections should be noted:

\section{Abstract, Results, Last line, which previously read:}

"The simulated data show the same trend as evidenced by greater change in exposures to oseltamivir (26 and $27 \%$ for $\mathrm{AUC}_{6}$ and $\mathrm{AUC}_{24}$, respectively) than $\mathrm{OSC}(\leq 6 \%)$."

\section{Should read:}

"The simulated data show the same trend as evidenced by greater change in exposures to oseltamivir (27 and $26 \%$ for $\mathrm{AUC}_{6}$ and $\mathrm{AUC}_{24}$, respectively) than $\mathrm{OSC}(\leq 6 \%)$."

Section 2.1, First line, which previously read:

"The effect of ethanol on oseltamivir hydrolysis to oseltamivir carboxylate (OSC) by CES1 was determined using recombinant human carboxylesterase-1b (BD
Supersomes $^{\mathrm{TM}}$, BD Gentest, San Jose, CA, USA) at a final protein concentration of $0.1 \mathrm{mg} / \mathrm{mL}$."

Should read:

"The effect of ethanol on oseltamivir hydrolysis to oseltamivir carboxylate (OSC) by CES1 was determined using recombinant human carboxylesterase-1b (BD Supersomes $^{\mathrm{TM}}$, BD Gentest, San Jose, CA, USA) at a final protein concentration of $0.05 \mathrm{mg} / \mathrm{mL}$."

Section 3.4, 2nd last line, which previously read:

"The simulated data show the same trend-oseltamivir exposure increased $\left(26\right.$ and $27 \%$ for $\mathrm{AUC}_{6}$ and $\mathrm{AUC}_{24}$, respectively) but no change in OSC exposure was observed."

\section{Should read:}

"The simulated data show the same trend-oseltamivir exposure increased (27 and $26 \%$ for $\mathrm{AUC}_{6}$ and $\mathrm{AUC}_{24}$, respectively) but no change in OSC exposure was observed."

The online version of the original article can be found under doi:10.1007/s40262-014-0160-3.

Z.-Y. Hu · S. C. Laizure · R. B. Parker $(\bowtie)$

Department of Clinical Pharmacy, University of Tennessee,

Health Science Center, College of Pharmacy, 881 Madison Ave.,

Room 346, Memphis, TN 38163, USA

e-mail: rparker@uthsc.edu

\section{A. N. Edginton}

Department of Pharmaceutical Sciences, University of Waterloo,

School of Pharmacy, Waterloo, ON, Canada 